\title{
O uso ideológico de metáforas multimodais pelo Jornal Nacional em matérias sobre Petrobrás
}

\author{
The ideological use of multimodal metaphors by tv globo's daily news program (Jornal Nacinal) \\ on petrobras
}

Teofilo Roberto Silva

Universidade Federal do Ceará - UFC - Ceará - Brasil

\begin{abstract}
$\longrightarrow$
Resumo: Neste trabalho discute-se como o Jornal Nacional representa a Petrobrás por meio da comunicação visual. O estudo teve com objeto de análise as imagens que o jornal exibiu ao longo das seis reportagens. São imagens relacionadas a estrutura física da estatal e ao esquema de corrupção do qual a Petrobras foi vítima. O arcabouço teórico consistiu na integração da Teoria da Metáfora Conceptual (LAKOFF; JOHNSON, 2003, 1999) e da Análise de Discurso Crítica (FAIRCLOUGH, 2003). Valemo-nos também da Gramática Visual (KRESS; VAN LEEUWEN, 2006) e da abordagem multimodal da metáfora (FORCEVILLE, 2009). A análise aponta para um discurso ideológico e eficaz em apresentar a Petrobrás como uma empresa em decadência. Ao analisar o uso ideológico que o Jornal Nacional faz de metáforas e metonímias através da comunicação visual, o estudo demonstrou a viabilidade da interface da TMC com a ADC numa abordagem multimodal.
\end{abstract}

Palavras-chave: Metáfora. Discurso. Ideologia. Multimodalismo. Petrobrás. Jornal Nacional.

Abstract: In this paper we discuss how TV Globo's daily news program - Jornal Nacional - represents Petrobras (the Brazilian state-owned oil company) through visual communication. The study analyzed images that Jornal Nacional exhibited throughout six reports. These are images related to the physical structure of Petrobras and to the corruption scheme the company was a victim of. The theoretical framework consisted of an interface between Conceptual Metaphor Theory (CMT) (LAKOFF, JOHNSON, 2003, 1999) and Critical Discourse Analysis (ADC) (FAIRCLOUGH, 2003). We also refer visual grammar (KRESS; VAN LEEUWEN, 2006) and to multimodal metaphor (FORCEVILLE, 2009). The analysis points to an ideological and effective discourse in presenting Petrobras as a company in decline. By analyzing Jornal Nacional's ideological use of metaphors and metonymy through visual communication, the study demonstrates the viability of an interface between CMT and ADC in a multimodal approach.

Keywords: Metaphor. Discourse. Ideology. Multimodalism. Petrobrás. Jornal Nacional. 


\section{Introdução}

A ideia de escrever este artigo surgiu quando, num restaurante, assistia, coagido pelas circunstâncias, ao Jornal Nacional (JN) enquanto esperava a pizza escolhida. Naquele dia, 23 de janeiro de 2016, um sábado, não encontramos outra mesa a não ser a que ficava a menos de dois metros de um aparelho de TV gigantesco. O som era alto, incomodava, às vezes ininteligível, por competir com as conversas do ambiente; a imagem, perfeita, irreparável nos detalhes característicos de uma transmissão digital em tecnologia FullHD. Chamoume à atenção os pequenos detalhes da imagem ampliados naquela tela enorme ao mesmo tempo em que preservava uma nitidez de qualidade impecável.

Não discutiremos em profundidade, neste trabalho, o conteúdo linguístico da notícia veiculada, a não ser com o propósito de contextualizar a discussão. Focaremos a análise sobre o discurso proposto pelos recursos visuais explorados na exposição de notícias do JN sobre a Petrobrás. Além daquele bloco, visto no restaurante, utilizaremos imagens de outros cinco blocos, disponíveis no site do Jornal Nacional, localizados numa rápida busca com o Google.

Motiva-nos também a debruçarmo-nos sobre o tema, a importância da opinião pública em relação à Petrobrás. A estatal, criada em 1953 por Getúlio Vargas, é certamente um dos maiores símbolos do patrimônio público brasileiro. Não por acaso, a sua privatização tem sido tema dos debates entre os candidatos à presidência da república nas últimas eleições, quando todos os candidatos, alinhados à opinião pública, negavam qualquer pretensão de retirar a empresa do patrimônio público para entregála ao patrimônio privado. A intensa exposição da Petrobrás pela mídia, retratando-a como vítima de um gigantesco esquema de corrupção, tem como efeito, e mais ainda como objetivo, mudar a opinião pública sobre empresa. A narrativa construída pelos meios de comunicação produziu a crise política que não apenas destituiu a presidente Dilma Rousseff da presidência, mas colocou no poder um grupo político com uma agenda extremamente neoliberal, um posicionamento político-econômico diametralmente oposto ao discurso eleitoral.

Temos por objetivos identificar a mensagem estruturada a partir das imagens e, consequentemente, propor possíveis efeitos ideológicos dessa mensagem sobre a construção das representações da Petrobrás pelos telespectadores.

Elegemos como base teórica a Análise de Discurso Crítica (ADC), como proposta por Fairclough (2003) e a Teoria da Metáfora Conceptual (TMC), de Lakoff e Johnson (2003, 1999). A ADC é uma proposta teórica de natureza interdisciplinar (FAIRCLOUGH, 2003). Um ponto central à ADC consiste no fato de buscar relações entre o discurso e as interações sociais. Dadas as diversidades e complexidades dessas interações, a interdisciplinaridade surge não apenas como uma possibilidade, mas como uma necessidade. Nesse trabalho, a interdisciplinaridade se realiza na TMC em consonância com a proposta de Hart (2014, p. 108), para quem "o verdadeiro lócus da produção ideológica é, portanto, não a linguagem em si, mas os processos cognitivos, incluindo os processos conceptuais, invocados pela língua" (tradução nossa).

Os dados escolhidos para análise, imagens expostas no Jornal Nacional, se traduzem num elemento de convergência tanto da TMC como da ADC. Nenhuma das duas propostas teóricas limita suas análises a dados exclusivamente linguísticos. Já em sua obra seminal, Metaphors we live by, Lakoff e Johnson (2003) defendem que a linguagem é apenas uma das formas de manifestação dos mapeamentos conceptuais, ou seja, a metáfora pode se manifestar por outros meios, não sendo exclusividade de construções linguísticas. Sobre a análise da comunicação visual, podemos nos referir a Kress e van Leeuwen (2001) no âmbito da ADC, e Forceville e Urius-Aparisi (2009) no campo da linguística cognitiva. Nesse trabalho, analisaremos as metáforas conceituais realizadas nas imagens do jornal, bem como o discurso ideológico estruturados a partir dessas metáforas. 


\section{Fundamentação Teórica}

Fairclough (2003), que encontrou na Linguística Sistêmica Funcional de Halliday uma das bases para a sua proposta de ADC, propõe três tipos de significados para os textos: o acional, o representacional e 0 identificacional. Esses significados correspondem, respectivamente, ao gênero, ao discurso, e ao estilo; eles não se realizam separadamente nos textos, mas interagem dialeticamente (FAIRCLOUGH, 2003). O tratamento desses significados de forma isolada se dá apenas por conveniência didática. Nesse trabalho, focaremos nas funções acional e representacional. Entendemos, entretanto, ser inviável analisar separadamente os dois tipos de significado em estudos como esse: ao mesmo tempo em que discutiremos as representações que as imagens constroem sobre a Petrobrás (significado representacional), argumentaremos que essas representações influenciam fortemente o modo como as pessoas se posicionam em relação à Estatal (significado acional).

Em consonância com Hart (2014), defendemos que a TMC se apresenta como ferramenta teóricometodológica útil à análise de discurso. Conforme o autor, "a metáfora pode ser explorada no discurso para promover uma ou outra imagem particular da realidade" (HART, 2014, p. 137). Hart (2014) destaca dois tipos de metáforas: as metáforas conceptuais, conforme Lakoff e Johnson (2003) e as mesclas conceptuais (conceptual blending) propostas por Fauconnier e Turner (2002). Essas últimas seriam relações conceptuais ad hoc, estruturadas de forma dinâmica e inovadora no momento da realização do discurso. As metáforas conceptuais, por outro lado, seriam mapeamentos relativamente estáveis entre domínios do conhecimento e experiências humanas, também referidos na literatura da linguística cognitiva como frames (FILLMORE, 1982). É sobre essa proposta de metáfora que trataremos nessa análise.

Foi em sua obra seminal Metaphors we live by, que Lakoff e Johnson (2003) propõem a Teoria da Metáfora Conceptual. O modelo teórico esboça a metáfora não como um fenômeno linguístico, mas como um processo mental que se manifesta na linguagem, sendo na realidade uma forma de o homem compreender 0 mundo. Através das experiências físicas, compreendem-se conceitos abstratos estabelecendo mapeamentos entre um domínio-fonte, mais concreto e um domínio-alvo, mais abstrato. Como exemplo, os teóricos demonstram que compreendemos relacionamentos em termos de viagem. O domínio-alvo RELACIONAMENTOS, mais abstrato é estruturado a partir de nossas experiências com VIAGEM, mais concretas. Na linguagem, as instâncias dos mapeamentos conceptuais se apresentam em frases como: Estamos numa encruzilhada; Esse relacionamento não vai muito longe; É melhor irmos com calma; dentre outras. A metáfora seria uma necessidade humana para compreendermos conceitos abstratos a partir de nossas experiências com o mundo físico.

A partir de expressões linguísticas como as mencionadas acima identifica-se a metáfora RELACIONAMENTOS SÃO VIAGENS, em que elementos do domínio VIAGEM mapeiam elementos do domínio RELACIONAMENTO. Construímos nosso conhecimento abstrato sobre RELACIONAMENTO a partir de nossas experiências físicas de VIAGEM. Lakoff e Johnson (2003; 1999) trabalham sua teoria a partir de exemplos linguísticos, mas como os próprios autores advogam, a metáfora é um fenômeno da cognição humana, por isso metáfora conceptual; consequentemente pode se instanciar através de outros recursos semióticos. O surgimento do paradigma linguístico-cognitivo dos estudos da metáfora tem produzido oportunidades para o estudo de metáforas não-verbais e multimodais (YU, 2009, p. 122).

Forceville e Urius-Aparisi (2009) tratam de metáforas multimodais, dentre elas as que se utilizam da comunicação pictórica. Esses recursos visuais têm participação no aspecto persuasivo do discurso. Numa afirmação mais enfática, os autores defendem O uso ideológico de metáforas multimodais

Todo discurso é persuasivo no sentido de apontar para algum tipo de efeito cognitivo, emocional ou estético, ou os três de uma só vez, sobre o público escolhido. Mas as mensagens puramente verbais e textuais na comunicação de massa na atualidade são frequentemente complementadas, ou mesmo 
substituídas, por informação em outro sistema de significação. Os materiais impressos (anúncios, manuais, livros de instrução, mapas, gráficos, cartoons, etc.) geralmente combinam, e estabelecem interações entre informação verbal e pictórica, ao mesmo tempo, a maioria dos filmes e programas de TV suplementarmente recorrem a música e som não verbal. (FORCEVILLE: URIUSAPARISI, 2009, p. 4)

Forceville (2009) define metáfora multimodal como mapeamentos em que o domínio alvo e o domínio fonte são, cada um, representado exclusivamente ou predominantemente por modos diferentes.

Aqui usamos o termo metáfora tanto em seu sentido amplo - referindo-se também a metonímias -, como em seu sentido específico, quando, por exemplo, expomos que a metáfora frequentemente é motivada por uma metonímia. Deve-se ressaltar ainda que a distinção entre metáfora e metonímia não é discreta, devemos compreender os dois fenômenos como pontos em um continuum dos processos de mapeamento (BARCELONA, 2000b, p. 16). Numa tentativa de definir os dois fenômenos, pode-se afirmar que a metáfora é estruturada por mapeamentos entre domínios distintos; já na metonímia, a relação se dá entre conceitos do mesmo domínio, em que um serve de acesso mental a outro (KÖVECSES, 2010). Um dos motivos da dificuldade em distinguir a metáfora da metonímia ocorre porque nem sempre é possível definir se os conceitos relacionados pertencem ou não ao mesmo domínio.

À luz do paradigma da TMC (LAKOFF; JOHNSON, 2003, 1999; FORCEVILLE, 2009), buscaremos nesse estudo demonstrar que a metáfora pode se realizar por meios não verbais, mais precisamente através de imagens utilizadas no $\mathrm{JN}$ ao noticiar escândalo de corrupção na Petrobrás. Ainda, ao expor a natureza persuasiva e ideológica da metáfora instanciada por imagens, temos por objetivo demonstrar que a TMC pode ser uma ferramenta útil à Análise de Discurso Crítica (HART, 2014). Esse argumento se torna ainda mais substantivo se considerarmos o objeto de análise aqui adotado - a comunicação visual: se a multimodalidade encontrou seu espaço na TMC (FORCEVILLE, 2009), o mesmo pode ser constatado no âmbito da ADC (KRESS; VAN LEEUWEN, 2006).

Kress e van Leeuwen (2006) defendem, em sua proposta da gramática visual, que assim como as gramáticas das línguas descrevem como as palavras se combinam em orações, sentenças e textos, a gramática visual descreve a forma como os elementos apresentados por meio de imagens pessoas, lugares e coisas - combinam-se em enunciados de maior ou menos complexidade e extensão. Segundo os autores, os elementos de uma representação pictórica mantêm relação de composicionalidade, ou seja, semelhante às relações sintagmáticas dos componentes linguísticos de uma frase, os componentes de uma comunicação visual mantêm relações internas na construção do seu significado como um todo.

Um aspecto da natureza composicional da comunicação visual se dá na relação dado-novo. Kress e van Leeuwen (2006, p. 181) demonstram que quando as imagens exploram significativamente 0 eixo horizontal, onde alguns elementos ocupam o lado esquerdo e outros o lado direito, os elementos postos à esquerda são representados como dado, enquanto os elementos à direita são representados como novo.

\section{Sinopse das imagens}

As imagens analisadas foram adquiridas por captura de tela dos vídeos disponíveis no próprio site do Jornal Nacional (https://g1.globo.com/jornalnacional/). Essas imagens da Petrobrás que o jornal exibe ao transmitir notícias da Operação Lava Jato (OLJ) segue certa sistematicidade. $\mathrm{Na}$ imagem mais frequente nos primeiros segundos da matéria, quando o apresentador anuncia o tema da notícia, surge no fundo a imagem de uma tubulação metálica gigantesca (supostamente um oleoduto ou gasoduto), ligada a um reservatório no qual se destaca a logomarca da Petrobrás (BR). A imagem ocupa uma área na tela proporcional a do apresentador do $\mathrm{JN}$, ao mesmo tempo em que se enquadra no centro da tela, junto ao âncora. Chama à atenção o alto nível de oxidação da tubulação, a estrutura se apresenta gravemente comprometida pela ferrugem (Figura 1A). 
Num efeito de zoom out, a imagem da tubulação segue um movimento de distanciamento ao mesmo tempo em que, ao aparecer a extremidade do duto, exibe-se o movimento de um forte fluxo de cédulas (de cem reais) saindo da tubulação (Figura 2).

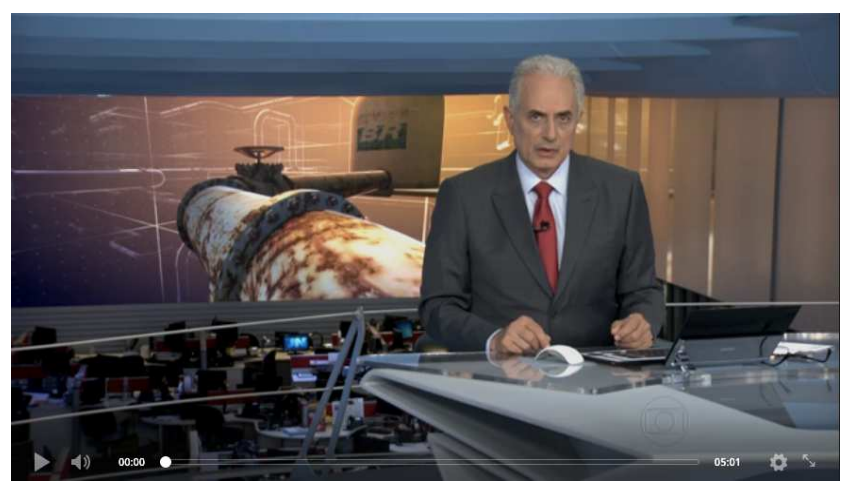

Figura 1A: Edição apresentada no dia 23 de janeiro de 2016.

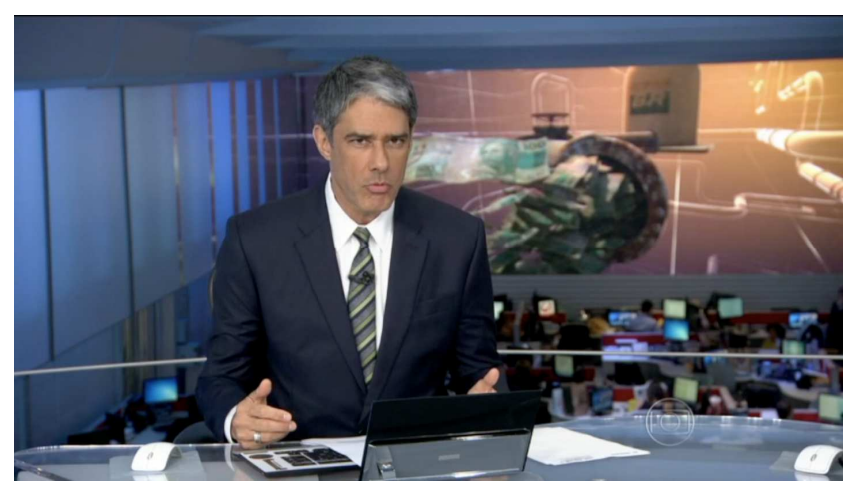

Figura 2: Edição exibida no dia 08 de março de 2016.

Ao longo das apresentações dos conteúdos das notícias, exibem-se outras imagens que supostamente retratariam a estrutura física da Petrobrás. Predominantemente, imagens de reservatórios e de oleodutos. Todos se destacam por apresentarem um alto grau de oxidação, transmitindo a ideia de uma estrutura física destruída (ou em processo de destruição) pela ferrugem. A essas imagens se somam as de dinheiro, cédulas de cem reais que se derramam aos montes do duto enferrujado.

Às imagens do objeto de corrupção (o dinheiro), combinam-se as dos rostos dos protagonizadores da corrupção. A sequência temporal em que a imagem da ferrugem antecede a imagem do dinheiro desviado equivale, em nosso entendimento, a sequência espacial da escrita ocidental da direita para a esquerda: visualizamos primeiro o conteúdo à esquerda e avançamos ao da direita (KRESS; VAN LEEUVEN, 2006).

Essas imagens não são apenas apresentadas no início das matérias, elas permanecem na tela como imagens de fundo enquanto a reportagem prossegue acrescentando informações ao telespectador. Há casos em que tais imagens permanecem na tela por pelo menos metade do tempo de exibição da matéria: dos 5 minutos e 2 segundos da edição de 23 de janeiro de 2016, as imagens foram exibidas por 2 minutos e 31 segundos; a edição do dia 20 de setembro durou 7 minutos e 28 segundos, quando as imagens permaneceram na tela por 4 minutos e vinte 20 segundos.

\section{Análise}

A metonímia...

A categoria analítica eleita neste trabalho é a metáfora, realizada de forma multimodal. O domínioalvo, a Petrobrás, é exaustivamente explicitado ao longo das matérias do $\mathrm{JN}$, ora analisadas: nas imagens apresenta-se a logomarca da empresa, com as letras "BR"; além disso, já nas primeiras frases, os apresentadores do jornal anunciam o assunto da matéria divulgada - esquema de corrupção na estatal. O domínio-fonte, portanto, é exposto por recursos multimodais: um de conteúdo pictórico - a logomarca da empresa, e outro de conteúdo linguístico - o anúncio vocalizado pelos âncoras.

Focaremos a análise mais detidamente nos domínios-fonte presente na comunicação visual que se realiza nas imagens da ferrugem destruidora da estrutura física da Petrobrás, e nas imagens das cédulas que se derramam dos dutos.

O frame evocado pelo conceito da FERRUGEM é bastante rico em suas implicações ideológicas. $O$ ferro, metal que se vincula mais prototipicamente à ferrugem do que outros metais, se faz presente na vida do homem desde, pelo menos, 1500 a.C. O conceito de FERRUGEM, portanto, se constrói nas sociedades ao longo de milênios. Numa passagem bíblica conhecida, Cristo orienta a seus seguidores para que não juntem tesouro na terra, "onde a traça e a ferrugem (grifo nosso) tudo consomem, e onde os 
ladrões minam e roubam"; vê-se, outrossim, que o símbolo negativo, de destruição ligado a ideia da ferrugem vem de um passado distante.

O domínio conceptual, ou frame (FILLMORE, 1982), evocado pelo conceito ferrugem envolve conceitos diversos, emergentes a partir de nossas experiências com a ferrugem. A oxidação deletéria ocorre em objetos metálicos no decorrer dos anos, por isso à ideia do objeto enferrujado se associa intimamente ao conceito de velhice: a oxidação e o envelhecimento são fenômenos concomitantes e inter-relacionados. Soma-se a isso, a constatação de que a ferrugem age destrutivamente sobre o metal, reduzindo estruturas, outrora robustas e altamente resistentes, a pó - o que era valioso não apenas perde o seu valor, mas, em casos extremos, deixa mesmo de existir.

Um objeto enferrujado também evoca a ideia de abandono. Sabe-se que a engenharia química produz substâncias anticorrosivas. São produtos utilizados para preservação de estruturas metálicas, com o propósito de prolongar a resistência do metal às ações da oxidação. O conceito FERRUGEM evoca um frame no qual se apresentam conceitos como DESTRUIÇÃO, VELHICE, ABANDONO, DESVALOR, PERDA. Conceitos que se ligam e se notabilizam pelo aspecto negativo, comum a todos. Deles, o mais saliente é o da destruição, por representar o estágio máximo da oxidação.

É com toda essa carga semântica que o JN representa a Petrobrás, uma das maiores produtoras de petróleo do planeta. Absolutamente em todas as imagens, a empresa é apresentada naquele jornal com a estrutura física corroída pela ferrugem. Construindo no telespectador a ideia de uma empresa destruída, sem valor, abandonada. A relação conceitual proposta pelas imagens é a da metonímia. Mais precisamente a da CAUSA PELO EFEITO, que se realiza na comunicação visual em FERRUGEM PELA DESTRUIÇÃO/DESVALORIZAÇÃO (e todos os conceitos negativos vinculados ao de FERRUGEM). Nisto vemos o poder argumentativo da imagem da ferrugem, uma vez que evoca uma sequência de conceitos extremamente negativos.

A Metáfora...
As imagens, entretanto, não se limitam a construir um conceito da estrutura física da Petrobrás. Se pela metonímia o JN destrói a reputação da estrutura física da empresa, pela metáfora o jornal se utiliza de recursos visuais para atacar a reputação moral da empresa. Referimo-nos às imagens das cédulas de cem reais que fluem aos montes dos dutos por onde supostamente fluiria petróleo ou gás. A metáfora proposta tem um poder argumentativo imenso por se fundamentar na metonímia analisada acima que, como vimos, é rica em seus desdobramentos de conceitos negativos. O tema da metáfora é a corrupção, representada pelas cédulas que se movimentam nos dutos.

Nas imagens, a ideia da corrupção realizada pelas imagens do dinheiro desviado interage com a ideia da degradação, produzida pelas imagens da ferrugem. A estrutura metafórica proposta aqui também se utiliza do frame da ferrugem: se a ferrugem representa, em seu sentido mais concreto, 0 conceito de DESTRUIÇÃO/DEGRADAÇÃO, em seu sentido mais abstrato relaciona-se ao conceito da CORRUPÇÃO, estruturando a metáfora CORRUPÇÃO É DEGRADAÇÃO (MORAL)/SUJEIRA/MANCHA. Nas Figuras 3A e $3 B$, a imagem da ferrugem além de sugerir 0 conceito de destruição, aponta para o conceito de sujeira. Na 3B, mais especificamente, a imagem é a do interior de um duto extremamente oxidado sugerindo a ideia de um esgoto por onde flui dinheiro desviado, ao invés de lama. À imagem do duto com seu interior enferrujado, semelhante a um esgoto, soma-se a imagem do dinheiro desviado que flui em seu interior. Estes recursos visuais licenciam a metonímia DESTRUIÇÃO É FERRUGEM e a metáfora CORRUPÇÃO É SUJEIRA: ambas ideologicamente usadas para conceitualizar a Petrobrás, buscando transmitir para o telespectador que a empresa é deteriorada, portanto sem valor, e corrupta.

A ocorrência dessas imagens no mesmo contexto não se dá de forma aleatória. Elas se relacionam sintagmaticamente (KRESS; VAN LEEUWEN, 2006), evidenciando pelo menos duas proposições: (1) A Petrobrás é uma empresa degradada; e (2) A Petrobrás é uma empresa corrupta. Nessa ordem. Os editores do jornal 
exploram as imagens de forma articuladamente sistemática. Em todas as imagens há presença da ideia da destruição, deteriorização, representada pela ferrugem. Na maioria (não absolutamente todas) das imagens, se apresenta também o símbolo máximo da corrupção - o dinheiro desviado. Mas esses dois elementos predominantes nas imagens - a ferrugem e o dinheiro - não são exibidos aos telespectadores de forma aleatória: quando ocorrem juntos, a imagem da ferrugem sempre antecede a imagem do dinheiro.

Do ponto de vista da cognição, essa sequência teria maior eficácia na construção da ideologia que o jornal impõe sobre o telespectador. A sequência se dá do conceito mais concreto para o conceito menos concreto, ou seja, utiliza-se a mesma ordem do desenvolvimento da cognição humana do ponto de vista ontogenético. Assimilamos primeiro os conceitos mais concretos e estes servem de fundamentos para construirmos os conceitos abstratos, sendo a metáfora um dos mecanismos envolvidos nesse processo (EVANS; GREEN, 2006). Nas imagens surge primeiro a ideia concreta da destruição, representada pela ferrugem, processo - e produto diretamente perceptível aos nossos sentidos, principalmente o da visão e do tato. Na sequência, apresenta-se a ideia abstrata da corrupção, representada pelo dinheiro que se derrama dos oleodutos. Vimos anteriormente que o frame da ferrugem participa na conceitualização metafórica da corrupção: CORRUPÇÃO É SUJEIRA/DEGRADAÇÃO MORAL.

A ideologia...

A imagens exercem um papel decisivo para garantir um alto poder de persuasão ao jornal. As imagens são exploradas de modo a representar conceitos concretos, como o da destruição, mas não apenas isso: as imagens servem ao propósito de apresentar ao telespectador um conceito abstrato, o da corrupção, dando-lhe roupagem de conceito concreto através do recurso visual, o telespectador vê a corrupção, representada pela imagem do dinheiro. Como destacam Kress e van Leeuwen (2006, p. 154), nós confiamos mais no que vemos do que no que ouvimos, "Vi com meus próprios olhos" inspira maior confiança do que "Ouvi com meus próprios ouvidos".
Os autores afirmam ainda que a credibilidade dos jornais (newspapers) está no fato de sabermos que as fotografias não mentem. $\mathrm{Na}$ análise em curso, entretanto, examinamos produtos da criação do homem através da computação gráfica, não fotos da realidade; as imagens apresentadas pelo JN são criadas e/ou manipuladas por programas de computador. Imagens que retratam um aspecto característico no noticioso: o da manipulação.

É através dessas imagens que 0 jornal estrutura metonímias e metáforas com objetivos ideológicos. Fairclough (2003, p. 9) define ideologias como "representações de aspectos do mundo que pode contribuir para estabelecer, manter e mudar as relações sociais de poder, dominação e exploração" (tradução nossa). A forma como o Jornal Nacional representa a Petrobrás impõe aos seus telespectadores um efeito evidente: levar a opinião pública a se posicionar favorável à privatização da estatal, mas não sem antes rotulá-la como uma empresa sucateada e sem valor.

O jornal furta-se ao seu suposto papel de informar por, de maneira intensa e sistemática, construir um discurso através de imagens que somente pejoram a Petrobrás. A comunicação visual vincula a corrupção apenas à Petrobrás, em si uma metonímia PARTE PELO TODO, pois os ilícitos foram praticados por alguns diretores da empresa. Os editores do JN noticiam sobre a Petrobras construindo um frame em que a empresa - uma das maiores produtoras de Petróleo do mundo - é retratada apenas como um palco de corrupção. Os ilícitos praticados por uma parcela de funcionários da cúpula do setor administrativo são material suficiente para o JN atacar a reputação da empresa como um todo: na comunicação visual, usada intensa e sistematicamente, o Jornal Nacional utiliza as imagens da destruição (pela ferrugem) e de corrupção vinculando-as somente a Petrobrás.

As notícias, em seu conteúdo geral, expõem esquemas de corrupção em que os vilões seriam indivíduos do mundo empresarial e do mundo político, ligados a empreiteiras e a partidos políticos. Das empreiteiras que prestariam serviços à Petrobrás o noticioso cita a Odebrecht, a OAS, Queiróz Galvão, 
Andrade Gutierrez, Mendes Júnior, UTC, Engevix e Camargo Corrêa. As matérias jornalísticas citam executivos da Petrobrás e das empreiteiras, além de políticos e partidos políticos que juntos movimentariam esquemas de corrupção. Apesar dessa diversidade de protagonistas da corrupção, a comunicação visual do Jornal Nacional ataca exclusivamente a Petrobrás: as imagens não estruturam nenhuma metáfora ou metonímia que conceptualize os reais envolvidos no esquema de corrupção. Mas não somente isso, os recursos visuais apresentam uma mensagem só: a Petrobrás é uma empresa fisicamente degradada e moralmente corrupta.

\section{Considerações Finais}

Não é possível ver o quanto os agentes da corrupção de fato prejudicaram a Petrobrás, mas é possível ver como o Jornal Nacional deprecia a estatal através da comunicação visual produzida por computação gráfica. O posicionamento do jornal não é gratuito. A notícia é o produto que tem o telespectador como destinatário quando o propósito é informar; ela se torna discurso ideológico, ou propaganda, quando o propósito é moldar a opinião pública com vistas a mudar as relações de poder; neste caso a 'notícia' não passa de um produto que a mídia vende aos interessados nessa mudança da relação de poder.

O discurso do JN sobre a Petrobrás busca pavimentar o caminho para a privatização da estatal. Nesta discussão nos detivemos na comunicação visual pelo seu alto poder de persuasão (KRESS; VAN LEEUWEN, 2006). O discurso linguístico pode nos levar a construção de uma imagem, mas no discurso visual a imagem já está construída e fugir dela, uma vez exposta, é impossível. Um exemplo é a nossa própria experiência, do dia 23 de janeiro de 2016, mencionada acima e que motivou essa análise. Para moldar a opinião pública o JN não apenas recorreu ao conteúdo (já discutido) e à forma das imagens (em altíssima resolução): os editores contaram também com a tecnologia que lhes permitiram expor as imagens por longos períodos durante as reportagens; como informamos anteriormente, pelo menos metade das reportagens que analisamos eram extensas e as imagens foram expostas na tela por pelo menos metade da duração da matéria. Temos uma ideia do impacto dessa estratégia quando lembramos que geralmente processamos e armazenamos conteúdos visuais com mais eficiência do que conteúdos linguísticos. Os detalhes dos conteúdos linguísticos foram diversos ao longo das matérias; mas o conteúdo das imagens que se repetiam por longos minutos em todas as reportagens era simples e somente um: a Petrobrás é uma empresa sucateada e corrupta.

Apesar desse conteúdo monotemático de corrupção que o JN aplica à estatal, no dia a dia dos brasileiros, a Petrobrás tem um significado bem diferente daquele das notícias repisadas nas matérias analisadas. No período da veiculação das notícias, a estatal produzia (conforme consulta em 13 de janeiro de 2017 no próprio site da empresa) mais de 2 milhões de petróleo por dia, sendo responsável por manter trafegando toda a frota nacional de veículos terrestres, marítimos e aéreos. Mas esse quadro, apesar de real, passa ao largo daquele pintado no JN, em que metonímias, metáforas e ideologias se interrelacionam na construção de uma narrativa. Nisto vemos o poder do discurso: a mídia tem conseguido reformular o frame da Petrobrás, de modo que, por ilógico que pareça, a empresa é associada, pela opinião pública muito mais à corrupção do que à produção do petróleo que mantém o país funcionando. Aliás, petróleo é o que jamais aparece nas imagens analisadas.

Do ponto de vista teórico, julgamos que a análise não deixa dúvida de que a TMC não é apenas uma teoria possível de se associar a ADC, mas que ela torna a análise de discurso extremamente perene, tornando essa interface indiscutivelmente viável. 


\section{Referências}

DIRVEN, R.; PÖRINGS, R (Orgs). Metaphor and Metonymy in Comparison and Contrast. New York: Mouton de Gruyter, 2003. 605 p.

EVANS, V.; GREEN, M. Cognitive linguistics: an introduction. Edinburgh: Edinburgh University Press, 2006. 830p.

FAIRCLOUGH, Norman. Analysing discourse: textual analysis for social research. London: Routledge, 2003. 269p.

FORCEVILLE, Charles; URIUS-APARISI, Eduardo. Non-verbal and multimodal metaphor in a cognitivist framework. New York: Mouton de Gruyter, 2009. 459p.

GEERAERTS, Dirk (Org). Cognitive linguistics: basic readings. Berlin: Walter de Gruyter, 2006. 485p.

HART, Christopher. Discourse, grammar and ideology: functional and cognitive perspectives. London: Bloomsbury, 2014, 216p.

KRESS, Gunther.; VAN LEEUWEN, Theo. Reading images: the grammar of visual design. London: Routledge, 2006. 291p.

LAKOFF, George; JOHNSON, Mark. Metaphors we live by. Chigago: The University of Chicago Press, 2003. 276p.

Philosophy in the Flesh. New York: Cambridge University Press, 1999. 624p.

\section{Anexos}

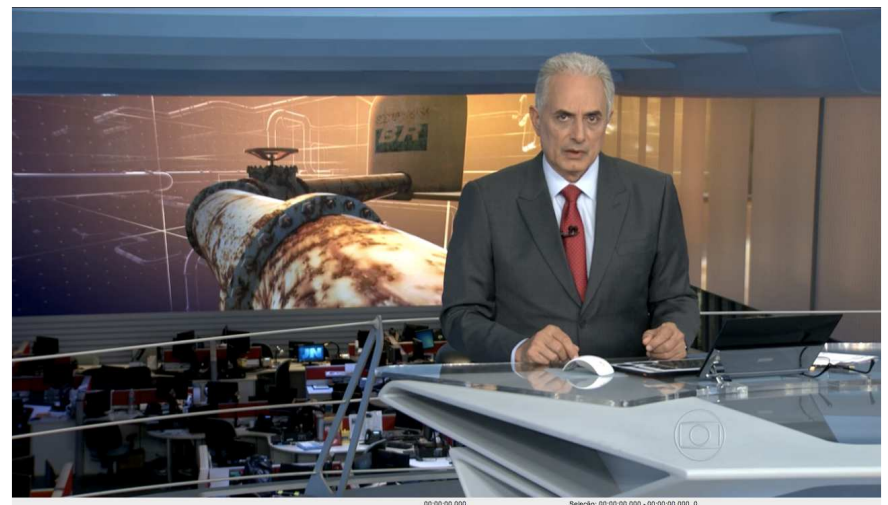

Figura 1A

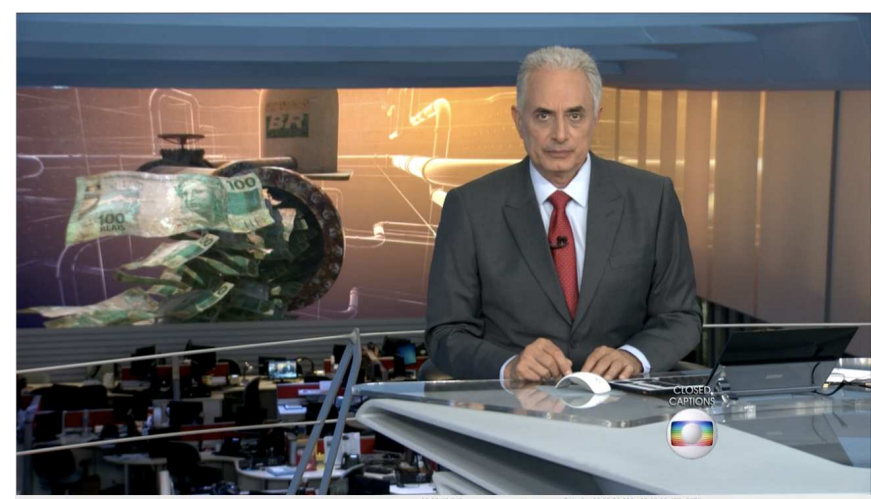

Figura 1B

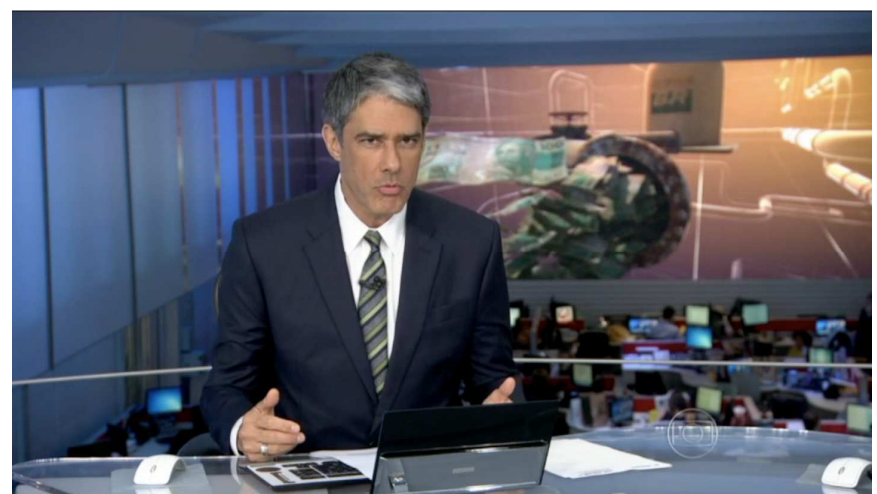

Figura 2

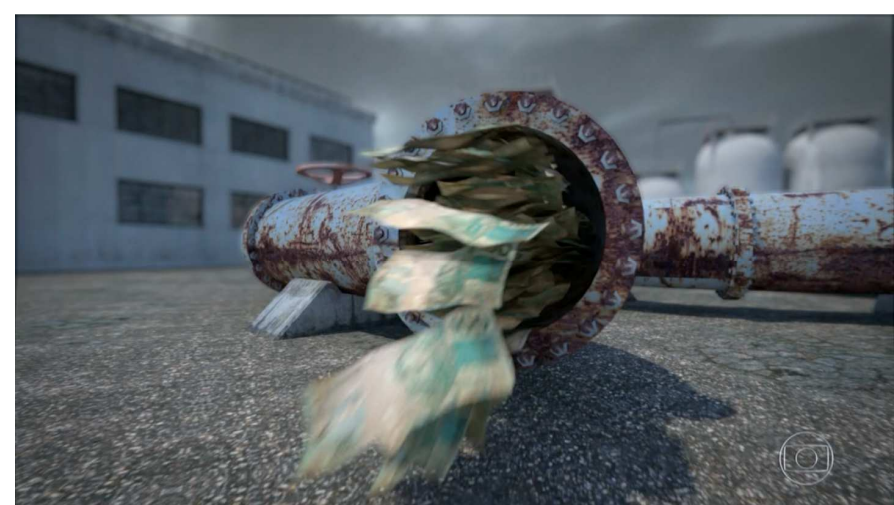

Figura $3 \mathrm{~A}$

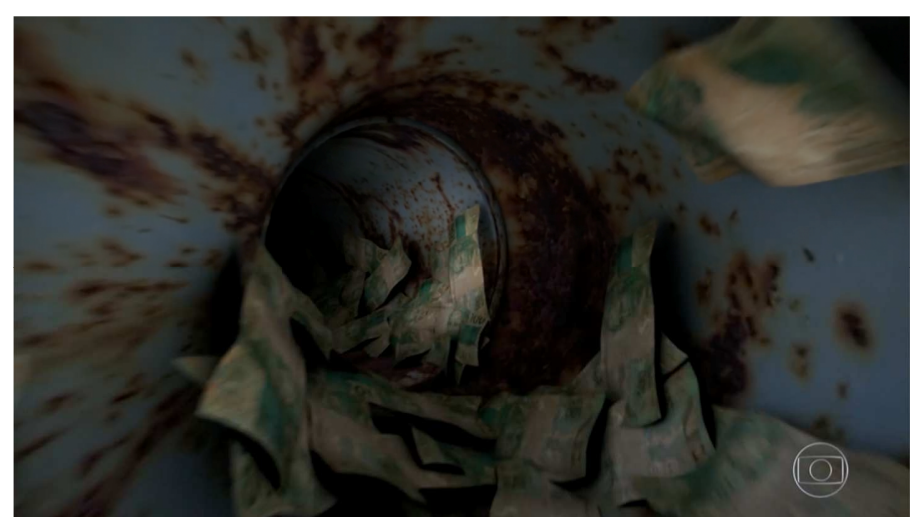

Figura 3B 


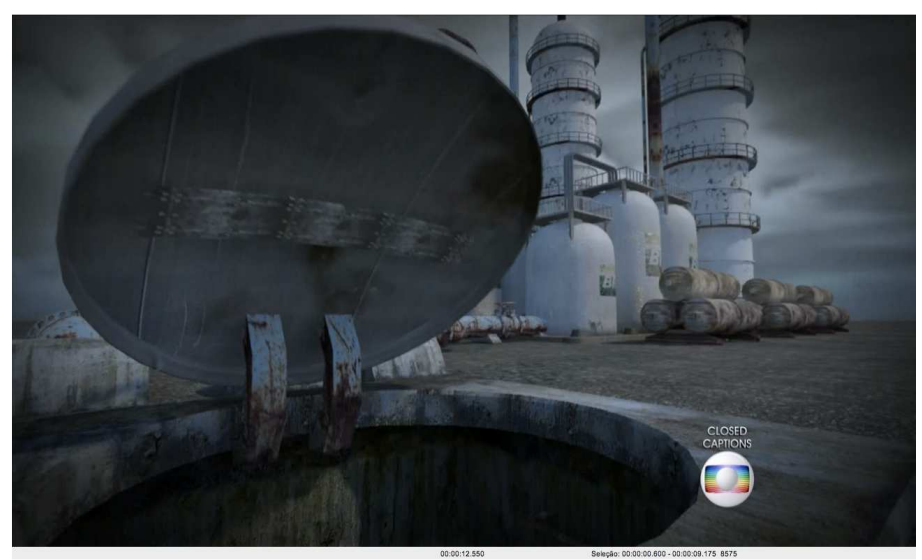

Figura 4

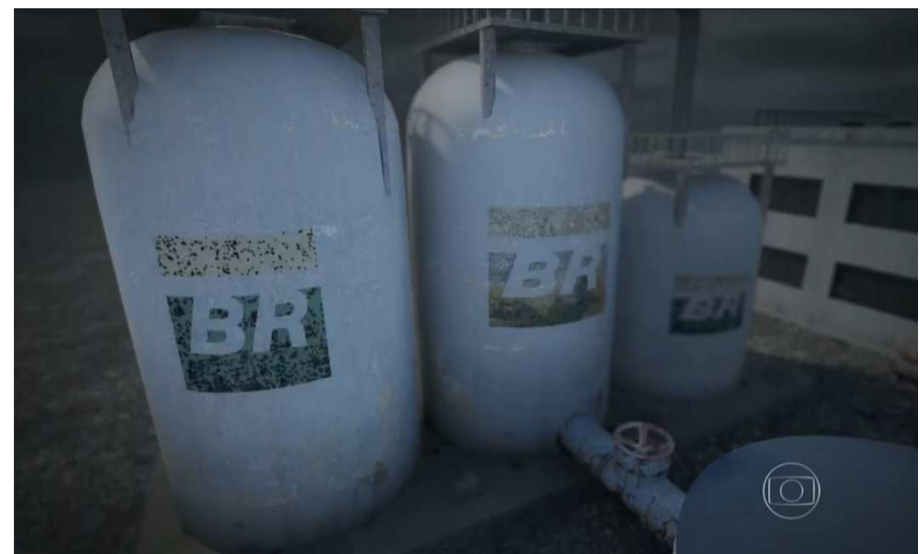

Figura 5

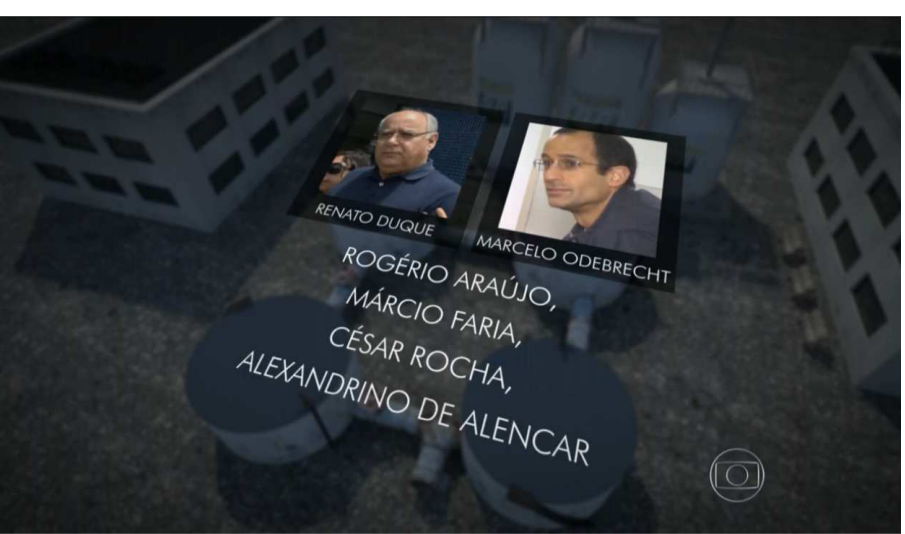

\section{Figura 6}

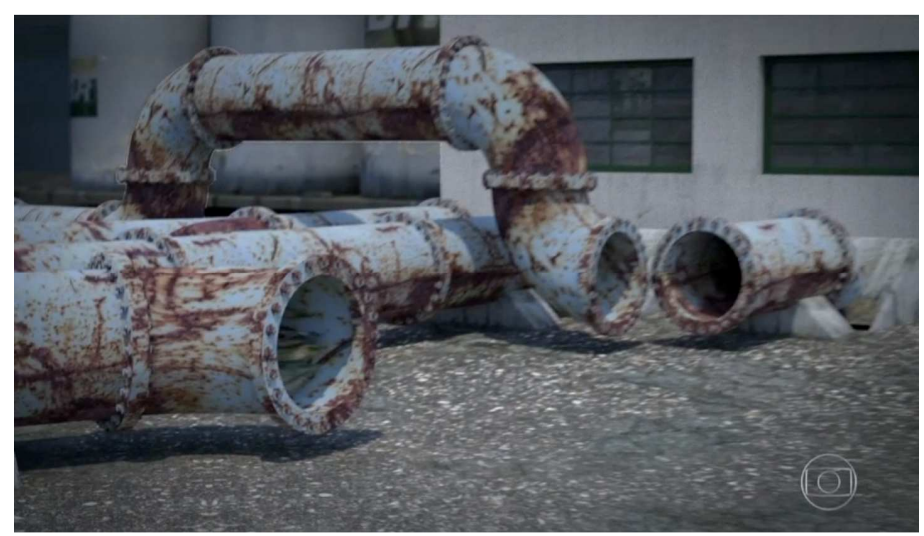

Figura 7A

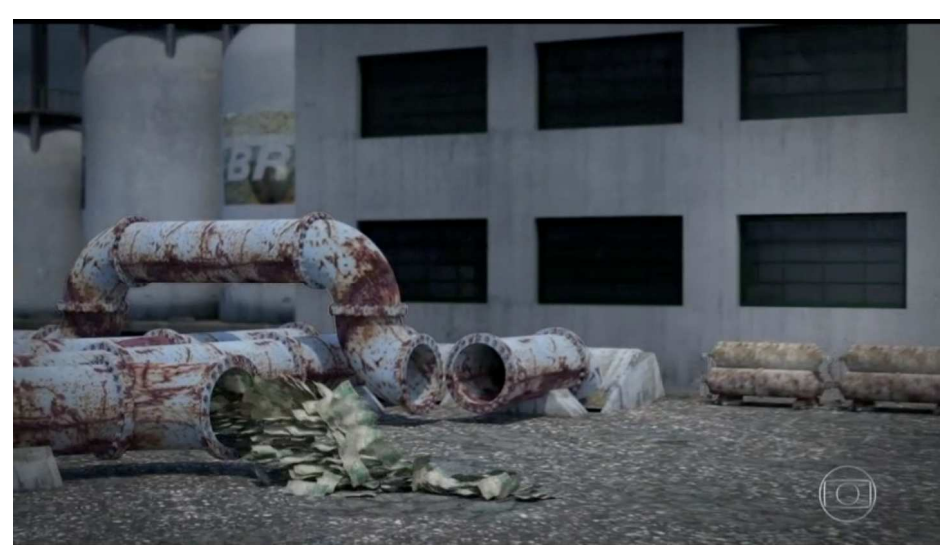

Figura 7B

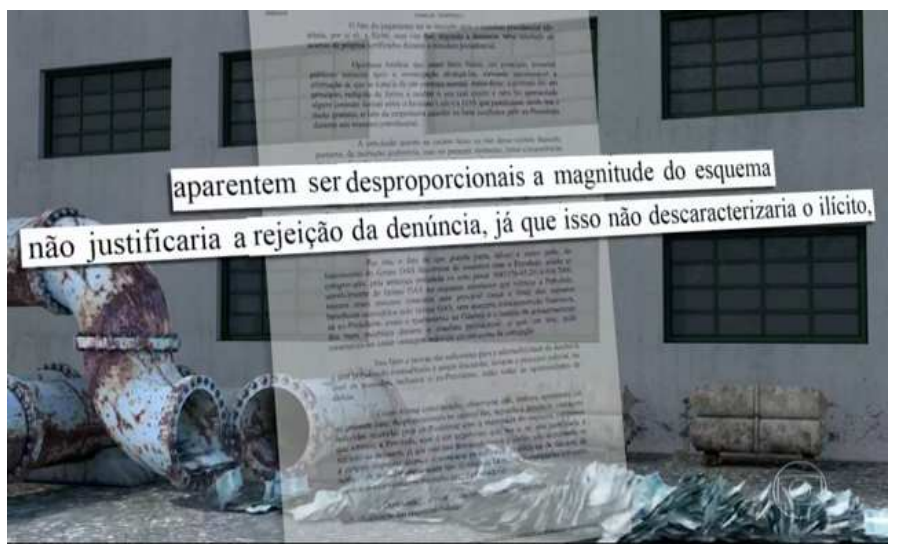

Figura 8

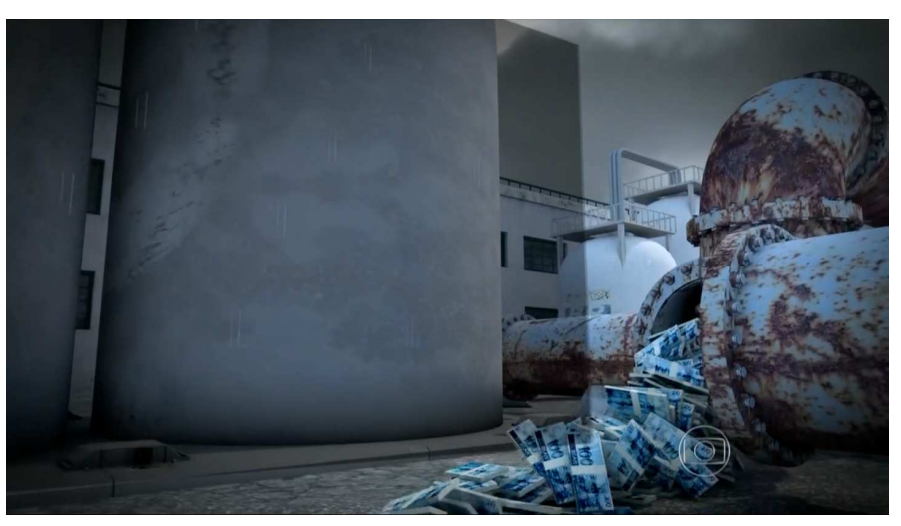

Figura 9 


\section{COMO CITAR ESSE ARTIGO}

SILVA, Teofilo Roberto. O uso ideológico de metáforas multimodais pelo Jornal Nacional em matérias sobre a Petrobrás. Signo, Santa Cruz do Sul, v. 44, n. 79, p. 54-64, jan. 2019. ISSN 1982-2014. Disponível em: <https://online.unisc.br/seer/index.php/signo/article/view/12836>. Acesso em: https://doi.org/10.17058/signo.v44i79.12836. 